\title{
TEST OF GROUND-SENSING DEVICES FOR MONITORING CANOPY VIGOUR AND DOWNY MILDEW PRESENCE IN VINEYARDS: FIRST QUALITATIVE RESULTS
}

\author{
Fabrizio Mazzetto, Aldo Calcante, Aira Mena, Pasqualina Sacco
}

\section{Introduction}

Precision Viticulture (PV) may be defined as the methodology that allows site-specific vineyard monitoring and management. Crop monitoring is a very important task in PV, because it concerns the gathering of information obtained through crop observations, such as phenological phases, nutritional state, plant health, production expectations, and production maps [Mazzetto 2006, Vieri 2010]. Presently, Remote Sensing (RS) is the most diffused techniques employed in PV systems. It concerns the elaboration of reflectance data collected by multispectral optical surveys in order to obtain virtual images of vegetation indices that may be correlated to phytosanitary plant status. Generally, multispectral systems collect images in few visible wavebands (green: $555-580 \mathrm{~nm}$, red: $665-700 \mathrm{~nm}$ ) and in the Near Infrared (NIR: 740$900 \mathrm{~nm}$ ), which are related to crop growth. Normally, reflectance data are used to calculate vegetation indices. As it is known, NDVI (Normalised Difference Vegetation Index) is one of the most studied of them. It is used to identify different vegetative vigour levels of crop canopies, on which production depends [Lamb 2001; Johnson 2003] and it is often obtained by aerial RS surveys.

RS data gathering strongly depends on climatic conditions and their use is a complex matter, particularly in viticulture because of: a) canopy architecture, b) grass or soil presence in the inter-row space, c) shadowing among the rows [Stamatiadis 2006]. In order to overcome RS limits, research was carried out to develop crop monitoring tools named "ground-sensing" technologies. Currently, there are several commercial active optical ground sensing devices avail-

Paper received 15.06.2010; accepted 13.12.2010

FABRizio MAZZETTO, full professor, Faculty of Science and Technology, Free University of Bolzano, Piazza Università, 5, 39100 Bozen (Italy); Aldo Calcante, researcher; Aira Mena, Phd; PasqualiNA SACCO, Phd; Department of Agricultural Engineering, Università degli Studi di Milano, Via G. Celoria 2, 20133 Milan (Italy). corresponding author: fabrizio.mazzetto@unibz.it,++390471017180 able: one of the most used devices is the GreenSeeker RT100 (Ntech Industries Inc., Ukiah, USA). Recently the GreenSeeker application in viticulture has been studied to characterise spatial distribution of vine vegetation vigour [Drissi 2009; Mazzetto 2009]. Groundsensing optical sensors were also investigated to detect disease symptoms on wheat and to discriminate between pathological and nutritional stresses [Moshou 2006]. In addition to multispectral devices, other types of sensors used in crop monitoring tasks have been studied. For example, ultrasonic sensors [Zaman 2006], or the LIDAR laser scanner [Gil 2007] are able to evaluate the variability of canopy volume within vineyards or orchards. Doruchowski [2009] studied a system to optimize the agrochemicals distribution in an orchard based on spectral and ultrasonic sensors. Other authors proposed the use of NDVI combined with ultrasonic sensors to estimate the biomass vigour of winter wheat [Scotford 2004] and cotton [Inamasu 2008].

In this study, a mobile monitoring system based on ultrasonic sensors for canopy thickness estimation and GreenSeeker for a multispectral vegetation investigation were developed. It intends to evaluate the performance of the proposed system with regards to the canopy volume derived from a set of ultrasonic sensors, its capability to represent the canopy evolution during the growth season, and its efficiency in detecting the dynamic diffusion of grapevine downy mildew through the integration of multispectral and ultrasonic data collected in vineyard conditions as similar as possible to normal field operations. Grapevine downy mildew is caused by Plasmopara viticola (Berk. et Curt.) Berl. and De Toni, and it is one of the most serious diseases of Vitis vinifera L.. It induces the appearance of pale yellow oil-spots in leaves and extended necroses on clusters. The spots eventually become necrotic and result in a premature defoliation of vines, mostly in severely affected vineyards. The macroscopic symptoms of the grapevine downy mildew are particularly evident and can allow a significant evaluation of the GreenSeeker device performance in detecting different disease levels in vineyards. 


\section{Materials and methods}

In order to evaluate the possibility to carry out a diagnosis in vineyards with the proposed mobile monitoring system, canopy health and vigour status were monitored simultaneously. To achieve this objective, tests were carried out during the 2007-2008 campaign in a commercial vineyard. Tests were conducted in three different growing season stages: June, 21 (T1, berries pea-sized), July, 9 (T2, bunch closure), July, 31 (T3, softening of berries).

Tests involved two groups of rows of cv Pinot Grigio at a commercial multi-wire vertical trellis vineyard located in Oltrepò Pavese:

- non-treated rows: plants that have never been treated with fungicides effective against $P$. viticola during the entire productive season (rows 1-3);

- treated rows: plants continuously protected against P. viticola (rows 4-7).

In this way, a great variability in vine status

was artificially caused between the two groups of rows in order to allow an accurate evaluation of the monitoring system.

Measurements of the layout of planting are reported in Table 1 for each monitored row.

Tests consisted in mobile surveys carried out with a $18 \mathrm{~kW}$ tractor equipped with the monitoring system mounted in front of it (Fig. 1). A DGPS double frequency receiver with Real Time Kinematic correction (Topcon mod. GB-500, Capelle a/d IJssel, The Netherlands), with in-field master station (Topcon mod. HiPerPro) was used to geo-reference data collected while travelling in the vineyard. Real time communication between the two receivers was conducted using two radiomodems.

The monitoring system included two coupled GreenSeekers and three couples of ultrasonic sensors mounted on a metallic frame that allowed the adjustment of the sensor's height (Fig. 1). Ultrasonic sensor signals were acquired through a 12 bit data acquisition device with 8 digital channels. The acquisition device was powered via USB $(5 \mathrm{~V})$ and connected to a data-logger. Optical data were directly acquired by the data-logger, which also stored sensor outputs and recorded GPS coordinates associated to each data acquisition (Fig. 2). Sampling frequency acquisition of the DGPS and GreenSeeker was set at $5 \mathrm{~Hz}$ during tests.

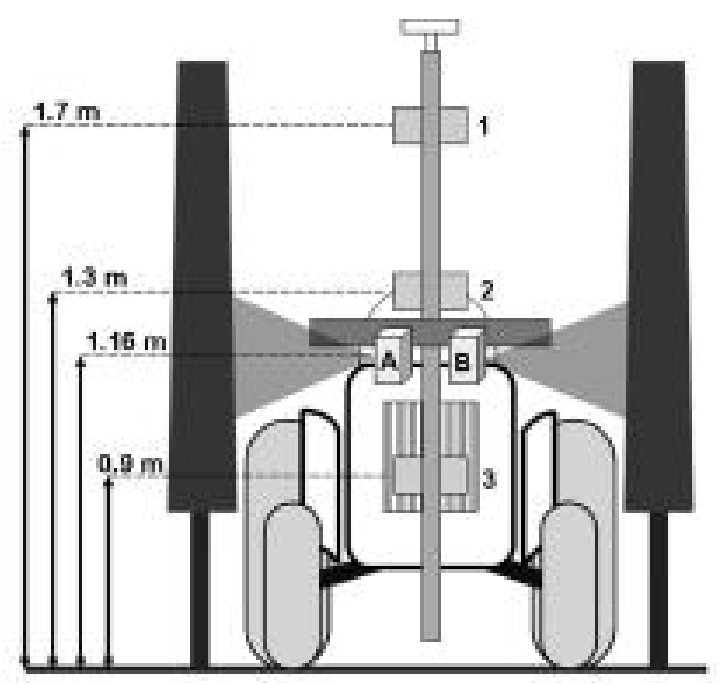

Fig. 1 - Schematic layout of the mobile monitoring system employed for tests in vineyard. A and B: GreenSeeker; 1, 2, 3: couples of ultrasonic sensors.

The GreenSeeker RT100 is a device with an active lighting optical sensor made up of an electroluminescent diode , LED, emitting high intensity light $660+/-$ $10 \mathrm{~nm}$ (red) and 770+/-15 nm (NIR) wavebands. LEDs are pulsed at $100 \mathrm{~Hz}$ with an average reading of $10 \mathrm{~Hz}$. The light reflected by leaves is captured by a silicon photodiode positioned in front of the device. Electronic filters remove background reflections. GreenSeeker computes NDVI values in real time.

The two GreenSeekers were positioned at $1.16 \mathrm{~m}$ above ground level, in order to investigate the vine fruit zone.

Each couple of ultrasonic sensors (Jameco Part. $n$. 134105, Senix Corp., USA) were mounted at three different heights $(\mathrm{H} 1=0.9 \mathrm{~m}, \mathrm{H} 2=1.3 \mathrm{~m}$, and $\mathrm{H} 3=$ $1.7 \mathrm{~m}$ ) above ground level. The entire vertical development of the vegetation wall could be investigated and the site-specific canopy volume derived from the horizontal distance to the foliage measured while travelling in the vineyard [Schumann 2005]. Ultrasonic sensors have a range of measurements between a minimum of $10 \mathrm{~cm}$ and a maximum of $152.4 \mathrm{~cm}$, with a $0.56 \mathrm{~cm}$ resolution. The beam pattern of the ultrasonic sensors was conical with a total angle of about 15 degrees. Ultrasonic sensors were placed $1.07 \mathrm{~m}$ from the vegetation wall, so the cone started at the

\begin{tabular}{cccc}
\hline Row & Row length $(\mathrm{m})$ & Inter-row distance $(\mathrm{m})$ & $\mathrm{n}^{\circ}$ of plants \\
\hline 1 & 90.88 & 2.29 & 76 \\
2 & 89.57 & 2.18 & 75 \\
3 & 92.28 & 2.30 & 77 \\
4 & 93.39 & 2.30 & 78 \\
5 & 94.43 & 2.29 & 78 \\
6 & 95.24 & 2.19 & 79 \\
7 & 95.49 & & 80 \\
\hline
\end{tabular}

TABLE 1 - Measurements of the layout of planting; vine-spacing mean value is $1.2 \mathrm{~m}$. 


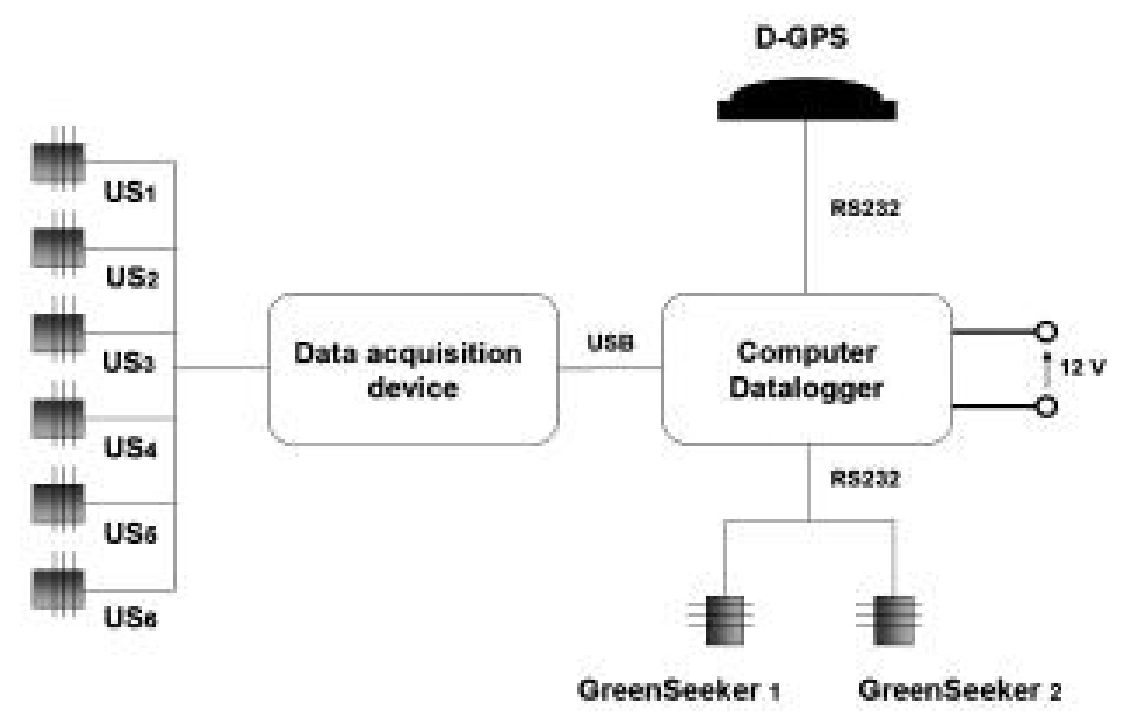

Fig. 2 - Diagram of the data acquisition integrated system for crop monitoring activities.

face of the sensor at about $0.04 \mathrm{~m}$ in diameter, diverging to $0.19 \mathrm{~m}$ in diameter when reflected by the canopy (Fig. 3). Frequency acquisition of ultrasonic sensors was set to $10 \mathrm{~Hz}$.

In order to calculate canopy thickness, ultrasonic sensors were calibrated before their use in vineyard.

The calibrating equation of distance vs. voltage $\left(r^{2}=0.99\right)$ is as follows:

$$
d_{V W}=13.696 \cdot V_{\text {out }}+14.941
$$

where:

$d_{V W}:$ sensor horizontal distance to the vegetation wall $(\mathrm{cm})$;

$V_{\text {out }}$ : output voltage $(\mathrm{V})$.

Ultrasonic sensors and optical tools of each pair were oriented in opposite directions in order to measure the horizontal distance to the foliage and the canopy spectral reflectance, on both sides of the tractor passing the inter-row track. During the tests, the tractor was driven at a speed of $3 \mathrm{~km} / \mathrm{h}(0.8 \mathrm{~m} / \mathrm{s})$, in order to obtain a spatial resolution of approx. $0.09 \mathrm{~m}$ and 0.17 $\mathrm{m}$ according to the working frequency of the system, respectively for ultrasounds and optical measurements.

During the same day, three passes were performed per inter-row track, two with the same driving directions and one with a reverse direction. This, in order to evaluate the repeatability of optical and analogue measurements, refers to the same vegetation wall, either using the same sensor in different passes, or using different sensors with regards to the same target.

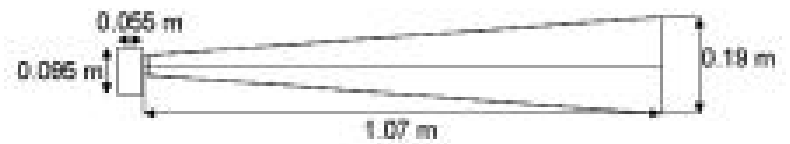

Fig. 3 - The conical beam pattern of the ultrasonic sensor between the face of the sensor and the vegetation wall.
Contextually, four replicate plots (A, B, C , D) were identified in non-treated rows (Fig. 4). Each plot consited of 12 vines. Each sampling point was georeferenced in order to match them with data automatically collected by the monitoring system. Disease visual assessments were carried out on each replicate plot on 50 randomly selected leaves per row side. A disease class was attributed to each leaf according to an 8class scale of symptomatic leaf area percentage. Disease classes range from 0 , healthy, to 7 (75-100\% of symptomatic surface). Classes are based on the extension of the organ surface showing downy mildew symptoms [Rho 2004] (Tab. 2). Then, the intensity of damage - i.e. the percentage infection index (I\%I) concerning $P$. viticola was calculated according to the equation proposed by Townsend [1943]:

$$
I \% I=\frac{\sum(n+v)}{\left(n_{c}-1\right) \cdot N} \cdot 100
$$

where:

$n=$ frequency of leaves for each disease class;

$v=$ numeric value of each disease class;

$n_{C}=$ number of classes;

$N=$ sample size.

Optical measurements collected by the GreenSeeker were processed through spatial interpolation procedures (using 3D-Field software) with the inverse dis-

\begin{tabular}{cc}
\hline Disease Class & Symtpomatic leaf surface $(\%)$ \\
\hline 0 & 0 (healthy leaves) \\
1 & $0-2.5$ \\
2 & $2.5-5$ \\
3 & $5-10$ \\
4 & $10-25$ \\
5 & $25-50$ \\
6 & $50-75$ \\
7 & $75-100$ \\
\hline
\end{tabular}

TABLE 2 - Classes used for disease visual assessment. 


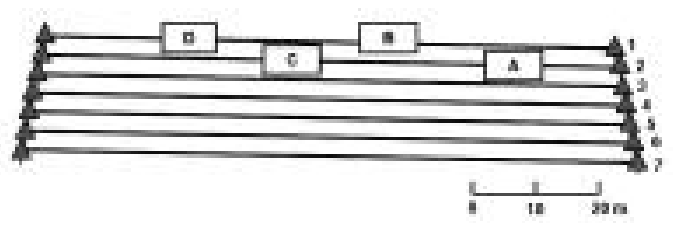

Fig. 4 - Spatial layout of plots identified within the vineyard for manual surveys and indicated with progressive alphabetical letters. Rows 1 thru 3 were not-treated with fungicides effective against $P$. viticola, whereas rows 4 thru 7 were continuously protected against $P$. viticola.

tance weighting method (IDW) in order to obtain NDVI maps [Milics 2008], which immediately show differences in vegetative development among plant groups.

At this processing stage, data gathered by ultrasonic sensors were used only to identify each monitored row and to eliminate turning-manoeuvre data points. The beginning and the end of each row was identified through an ultrasonic sensors voltage measurement chart analysis, which highlighted constant and saturated signals corresponding to data collected outside the rows. The preliminary data screening was necessary because NDVI values associated with turning-manoeuvres affect the accuracy of the interpolated maps.

NDVI maps were preliminary produced for the entire monitored area within the vineyard and then for each plot. In each plot, NDVI maps were compared to I\% I maps produced through the spatialization of I\%I values calculating from disease visual assessment.

Concerning ultrasonic sensors, voltage data were converted into distance measurements according to Equation 1, then measurement repeatability was verified according to the same procedure used for an analysis of NDVI values. After repeatability verification, for a point $r$ of the vineyard, Ultrasonically measured Canopy Thickness UCT $(r)$ at each measurement height can be calculated as: where:

$$
U C T(r)=R S-\left[d_{A}(r)+d_{B}(r)\right]
$$

$R S=$ row spacing $(\mathrm{m})$;

$d_{A}(r)$ and $d_{B}(r)=$ foliage-sensor distances $(\mathrm{m})$ at point $r$, measured from the opposite sides of the canopy during two contiguous tractor passes.

Since ultrasonic sensors provide data directly linked to distance measurements, an evident but remarkable property of Equation 3 is that it does not need any species- or cultivar-specific calibration. Nevertheless, it has to be underlined that results of Equation 3 are valid, subject to the assumption that the tractor deviations from the inter-row axis are negligible. Contextually to automatic surveys with the ultrasounds, MCT (Manually measured Canopy Thickness) as measured on four selected plots (4.5 m long) located on non-treated rows (Fig. 4, A, B, C, D). Measurements were conducted according to a sample grid at the three heights investigated by ultrasonic sensors, in order to compare MCT and UCT, and to verify that UCT values corresponded to the actual canopy width.

\section{Results and discussion}

\subsection{Optical data}

In order to evaluate result reliability, repeatability of NDVI measurements was verified through determination coefficient computation $\left(r^{2}\right) ; r^{2}$ is within a minimum of 0.70 and a maximum of 0.80 for data collected when driving in the same direction and in the reverse direction (Fig. 5). NDVI maps were then produced. Fig. 6 refers to three monitoring surveys carried out in three different growing stages: June, 21 ( $\mathrm{T} 1$, berries pea-sized), July, 9 (T2, bunch closure), July, 31 (T3, softening of berries). The NDVI representation scale is within a minimum of 0 to a maxi-
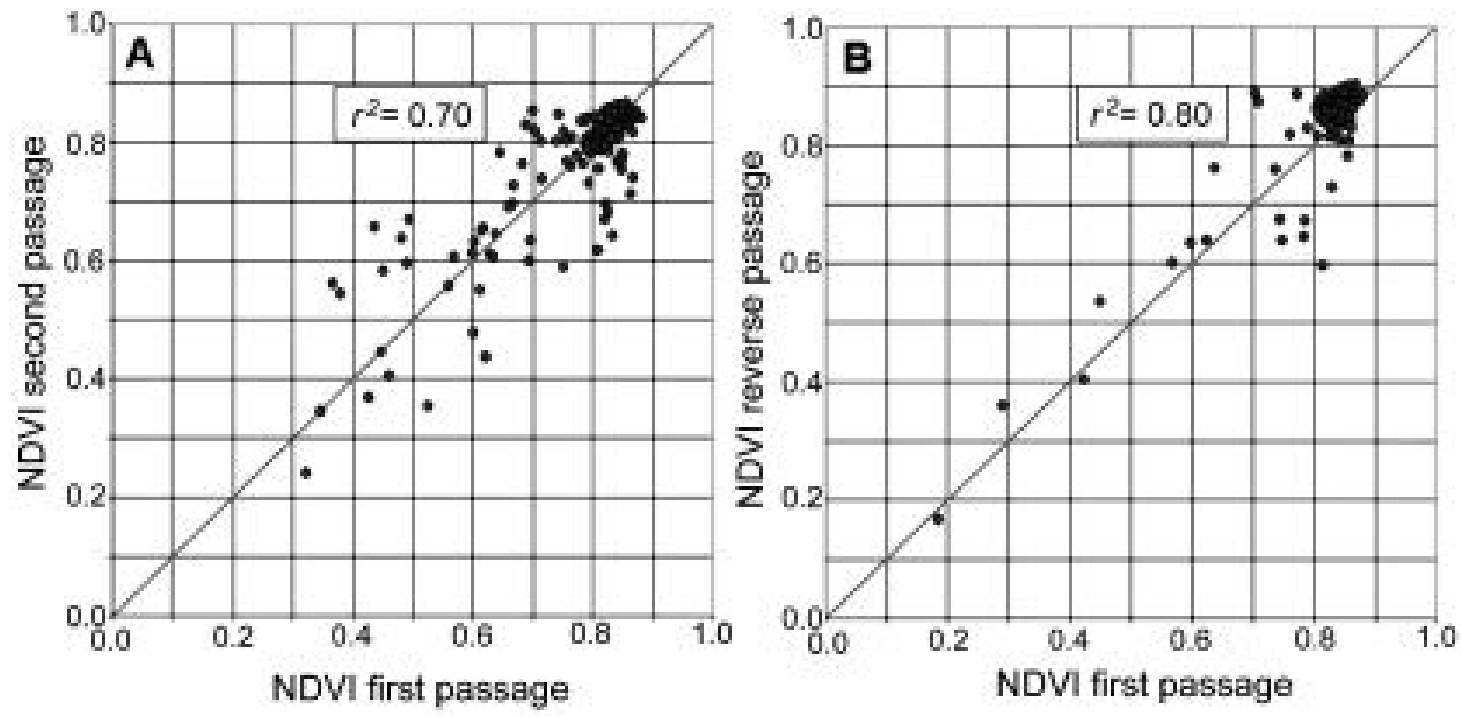

Fig. 5 - Correlation between NDVI values measured during two subsequent passages of the tractor performed in the same direction (chart A) and one in the reverse direction (chart B). 


\begin{tabular}{cccccc}
\hline Date & Replicate 1 I\%I & Replicate 2 I\%I & Replicate 3 I\%I & Replicate 4 I\%I & Average I\%I \\
\hline June, 21 & 13.5 & 6.9 & 4.1 & 6.3 & 7.7 \\
July, 09 & 45.3 & 27.8 & 29.7 & 26.4 & 32.3 \\
July, 31 & 71.9 & 60 & 62.43 & 41.43 & 58.9 \\
\hline
\end{tabular}

TABLE 3 - The downy mildew I\%I assessed on leaves in the untreated four replicate plots.

mum of 1 , divided into classes of size 0.02 . The threshold value applied is 0.60 and it was selected in order to emphasise the small differences in vegetative vigour level within the vineyard. This value has been identified through the examination of values proposed in literature and the frequency analysis of data collected during preliminary tests carried out in greenhouse [Mazzetto 2009]. NDVI maps clearly show differences in vegetation conditions in the two groups of rows. Their comparison highlights that several zones of the non-treated rows (1-3) were characterised by low vegetation vigour associated with a high incidence of grapevine downy mildew, as confirmed by disease assessments listed in Table 3. Conversely, in the treated rows (rows 4-7) there was a high vigour level, that increased until July 9 because of the side shoot development. Afterwards, the vigour level also decreased in the treated part of the vineyard due to the natural grapevine phenological development.

\subsection{Ultrasonic data}

At first, measurement repeatability was verified according to the same procedures used for the NDVI value analysis. Good repeatability was also observed in this case $\left(r^{2}=0.72\right.$ for data collected when driving in the same directions; $r^{2}=0.77$ for data collected when driving in reverse directions Fig. 7).
A first analysis of canopy semi-thickness measured on tied and non-tide vines was carried out. In particular, in non-tied vines, the large part of the vegetation was concentrated at two lower investigated heights $(0.90$ and $1.30 \mathrm{~m})$. On the contrary, on completely tied vines, less differences in canopy thickness in the three investigated zones were observed. According to these preliminary positive results, UCT was compared to MCT through a determination coefficient and twotailed Student t-test at a 5\% level of significance for a two-sample, assuming equal variance (tests on the variance ratio confirmed that variances do not differ significantly). Data analysis was carried out on all data sets firstly distinguished by monitoring day (T1, T2, T3) and then by the investigated height (H1, H2, H3). In both cases, the statistical analysis confirmed that the UCT values were not significantly different from the MCT values (Tab. 4 and Tab. 5). Tab.4 shows that the mean value of canopy thickness (CT) (computed on the entire data set) varied during the monitoring period. It was between a minimum of $0.25 \mathrm{~m}$ (T1) and a maximum of $0.29 \mathrm{~m}$ (T2), and it increased as the growing season progressed. The mean CT values observed during the experimentation are included within a range of $0.25-0.35 \mathrm{~m}$, which normally corresponds to an optimal canopy density of 2.5-3 leaf layers, as demonstrated by Oberti [2007]. Regarding the analysis conducted on all datasets distinguished by investigated
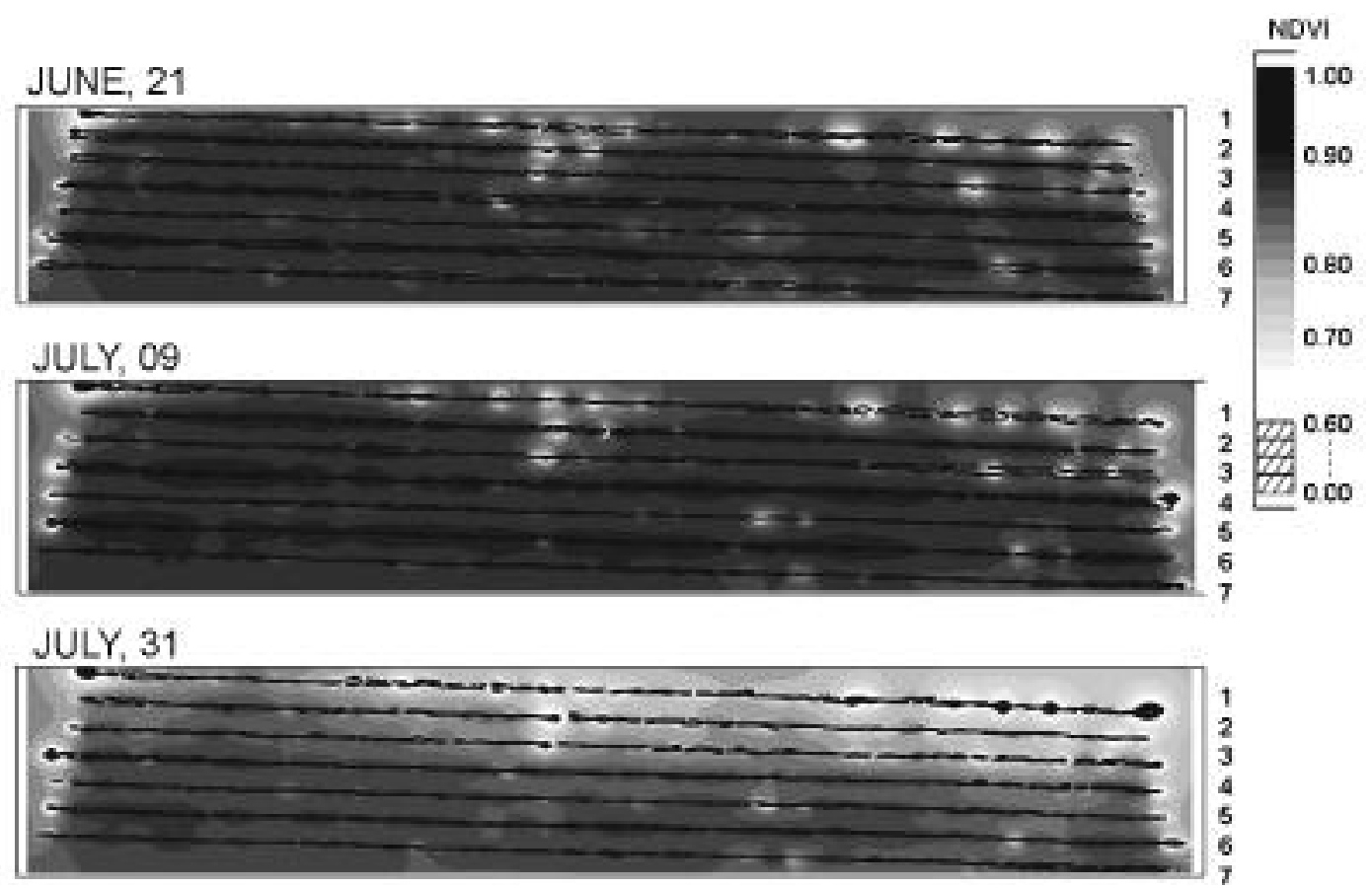

Fig. 6 - The NDVI maps obtained from data collected by GreenSeeker during T1, T2, T3 tests. 

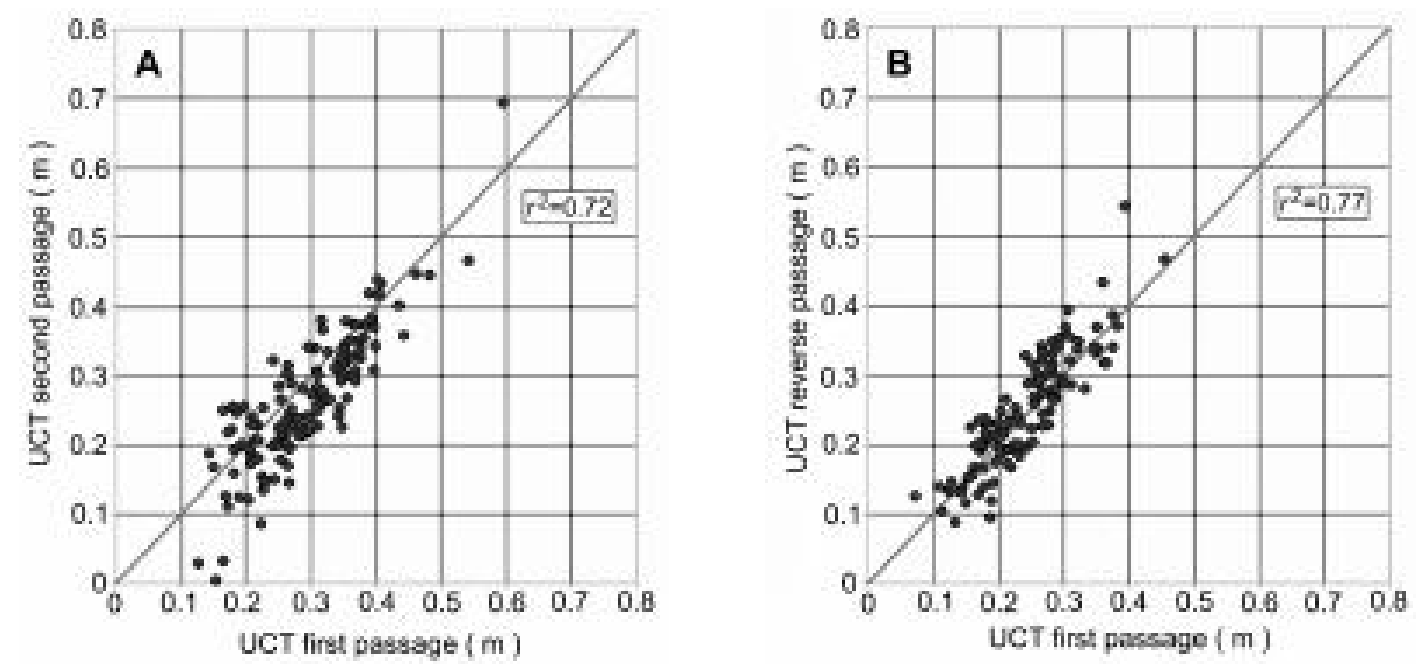

Fig. 7 - Correlation between canopy thickness measured during two subsequent passages performed in the same direction (chart A) and one in the reverse direction (chart B).

height (Tab. 5), the UCT mean value reached its maximum $(0.31 \mathrm{~m})$ at $\mathrm{H} 1$, which corresponds to the fruit zone, and its minimum $(0.20 \mathrm{~m})$ at $\mathrm{H} 3$. At the top of the vegetation wall, UCT showed some negative values because of the electronic noise that sometimes occurred in case of canopy absence (Fig. 8). Furthermore, the correlation between UCT and MCT values decreased with the increasing height, reaching the minimum value $\left(r^{2}=0.48\right)$ at the top of the canopy. This fact could be explained by the higher error incidence in ultrasonic data caused by the thinning of the foliage in the upper part of vines, and by the detection and distance measurements of some extended shoots at the top of the canopy that were not considered in manual measurements.

\subsection{Infected area identification}

I\% I maps of $P$. viticola were produced according to the results of the disease assessments carried out in each monitored plot. A visual analysis of the comparison between I\%I and the NDVI map was conducted.
It showed a good correspondence between NDVI values and the visually assessed disease incidence, even if at a qualitative level (Fig. 9). In fact, both NDVI and I\%I maps show discoloured areas indicating low NDVI values and grapevine downy mildew incidence in the same zones of the plot. Nevertheless, in Fig. 9, low NDVI values that have no correspondence to infected areas can be observed in the right zone of the map.

Then, NDVI values and UCTs calculated on plots were compared through a visual analysis of signals.

Since the comparison highlighted lack of vegetation along the rows corresponding to areas presenting both low UCT and NDVI values (indicating critical vegetation conditions) but no disease symptoms, the identification of the downy mildew affected areas (high UCT values, low NDVI values, presence of infection) was correctly achieved. In fact, in areas characterised by lack of vegetation, NDVI indicates critical vegetation conditions, but no grapevine downy mildew symptoms were detected by the disease visual assessment. Therefore, the contextual use of UCT and

\begin{tabular}{|c|c|c|c|c|c|c|c|c|c|}
\hline \multicolumn{2}{|c|}{ Monitoring day ${ }^{(1)}$} & $\mathrm{n}^{(2)}$ & Method & Minimum (m) & Maximum (m) & Mean $(\mathrm{m})$ & $t^{(3)}$ & $\mathrm{DF}^{(4)}$ & $r^{2(5)}$ \\
\hline \multirow{2}{*}{\multicolumn{2}{|c|}{$\mathrm{T} 1$}} & 267 & $\mathrm{MCT}$ & 0 & 0.70 & 0.25 & -0.05 & 532 & 0.60 \\
\hline & & 267 & UCT & 0 & 0.74 & 0.25 & & & \\
\hline \multicolumn{2}{|r|}{$\mathrm{T} 2$} & 270 & UCT & 0 & 0.80 & 0.29 & & & \\
\hline \multirow{2}{*}{\multicolumn{2}{|c|}{$\mathrm{T} 3$}} & 277 & MCT & 0 & 0.81 & 0.28 & -1.78 & 552 & 0.69 \\
\hline & & 277 & UCT & 0 & 0.68 & 0.26 & & & \\
\hline \multicolumn{2}{|r|}{ Total } & 814 & UCT & 0 & 0.80 & 0.27 & & & \\
\hline \multicolumn{10}{|c|}{$T 1=$ test of June, $21 ; T 2=$ test of July, 9; T3 = test of July, 31} \\
\hline (2) & \multicolumn{9}{|c|}{$n=$ number of sample points } \\
\hline (3) & \multicolumn{9}{|c|}{ Two-tailed Student t-test for two sample assuming equal variance } \\
\hline (4) & \multicolumn{9}{|c|}{$D F=$ degree of freedom } \\
\hline
\end{tabular}

TABLE 4 - Summary statistics for manual and ultrasonic canopy thickness on different monitoring days. 


\begin{tabular}{ccccccccc}
\hline $\begin{array}{c}\text { Investigated } \\
\text { height }{ }^{(1)}\end{array}$ & $\mathrm{n}^{(2)}$ & Method & Minimum (m) & Maximum (m) & Mean (m) & $\mathrm{t}^{(3)}$ & $\mathrm{DF}^{(4)}$ & $r^{2(5)}$ \\
\hline $\mathrm{H} 1$ & 284 & MCT & 0 & 0.71 & 0.31 & -0.69 & 566 & 0.71 \\
& 284 & UTC & 0 & 0.80 & 0.31 & & & \\
$\mathrm{H} 2$ & 294 & MCT & 0 & 0.81 & 0.29 & -1.00 & 586 & 0.51 \\
& 294 & UCT & 0 & 0.75 & 0.28 & & & \\
$\mathrm{H} 3$ & 236 & MCT & 0 & 0.74 & 0.20 & -0.04 & 470 & 0.48 \\
& 236 & UCT & 0 & 0.60 & 0.20 & & & \\
\hline Total & 814 & MCT & 0 & 0.81 & 0.27 & -0.94 & 1626 & 0.61 \\
\hline
\end{tabular}

(1) $\mathrm{HI}=0.9 \mathrm{~m} ; \mathrm{H} 2=1.3 \mathrm{~m} ; \mathrm{H3}=1.7 \mathrm{~m}$
(2) $n=$ number of sample points
(3) $T$ wo-tailed Student $t$-test for two sample assuming equal variance
(4) $\mathrm{DF}=$ degree of freedom
(5) $r^{2}=$ determination coefficient

TABLE 5 - Summary statistics for manual and ultrasonic canopy thickness at different investigated heights.
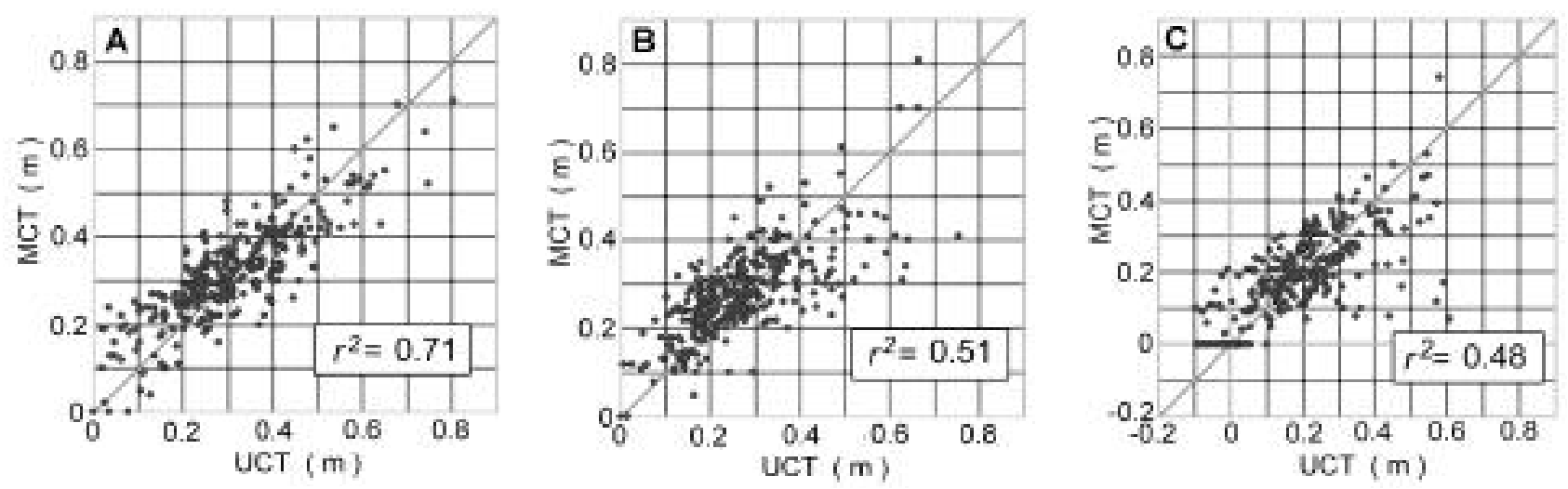

Fig. 8 - Correlation between UCT and MCT at three investigated heights. Charts A, B, and C refer to $\mathrm{H} 1, \mathrm{H} 2$, and $\mathrm{H} 3$ respectively.

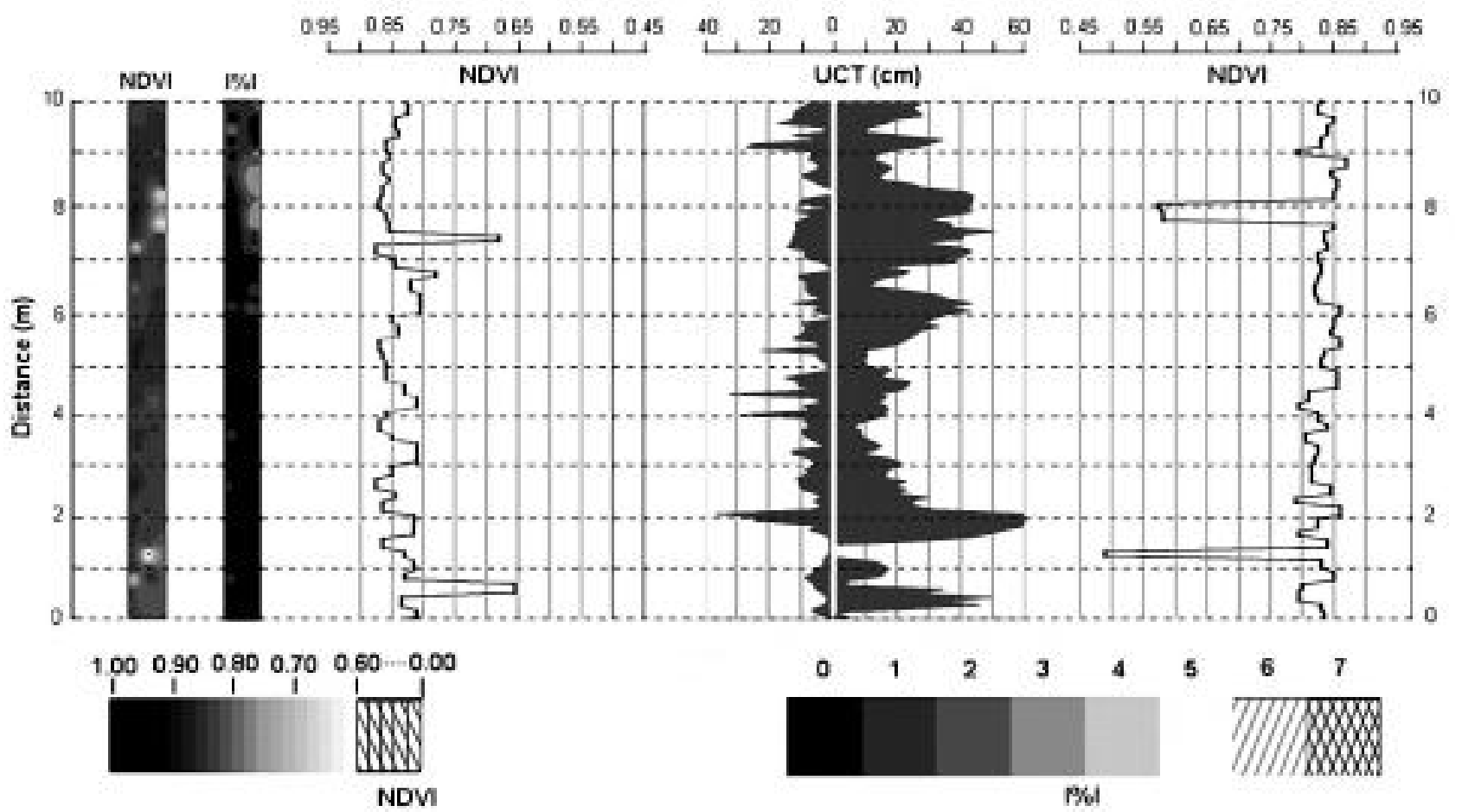

Fig. 9 - NDVI and I\%I maps of parcel A obtained from the spatial interpolation of T1 data and the comparison of NDVI and UCT signals for the identification of disease affected areas. 
NDVI measurements allowed the identification of downy mildew affected areas characterised by low NDVI but high UCT values, which highlights the presence of vegetation.

\section{Conclusions}

The goal of this work was to test a mobile monitoring system which implements optical devices GreenSeeker RT100 - and ultrasonic sensors for ground sensing surveys in viticulture, in particular for the diagnosis of grapevine downy mildew directly in vineyards.

Results obtained through the GreenSeeker could be considered more than acceptable. The GreenSeeker usefulness is confirmed by measurement repeatability and the positive results achieved with open-field data elaboration. NDVI maps produced at the vineyard scale, could be considered an effective management tool that shows vineyard areas characterised by different vigour levels; scouting operations can be targeted to these critical areas.

Results confirmed a good measurement repeatability for ultrasonic data, too. The comparison between UCT and MCT values indicates that there is no significant difference between the two types of measurements. Results highlight that an automated ultrasonic system can measure canopy thickness rapidly and reliably in vineyards.

An initial qualitative analysis that considered simultaneously measured NDVI and UCT values was promising. In fact, it allows the discrimination of zones characterised by lack of vegetation (low UCT values) or the presence of downy mildew symptoms (high UCT values). In this way, the identification of downy mildew affected areas was possible. Therefore, the integration of the two types of data represents the first step for the application of a diagnosis at the field level.

\section{References}

Drissi R., Goutouly J.P., Forget D., Gaudillère J.P., Nondestructive measurements of grapevine leaf area by ground normalized difference vegetation index. Agronomy Journal, 2009,101(1), 226-231.

Doruchowski G., Balsari P., Zande J. van de., Development of a crop adapted spray application system for sustainable plant protection in fruit growing. Acta Horticulturae, 2009, 824, 251-259.

Gil E., Escolà A., Rosell J.R., Planas S., Val L., Variable rate application of plant protection products in vineyard using ultrasonic sensors. Crop Protection, 2007, 26, 1287-1297.

Inamasu R.Y., Tangerino G.T., Porto A.J. V., Luchiari A., Schepers J.S., Shanahan J.F., Francis D.D., Simões M.S., Using active sensor and ultrasound sensor readings to assess plant $\mathrm{N}$ status. Proceedings of the 9th International Conference on Precision Agriculture, 2008, Denver, Colorado, USA, 20-23 July.
Johnson L.F., Roczen D.E., Youkhana S.K., Neemani R.R., Bosch D.F., Mapping vineyard leaf area with multispectral satellite imagery. Computers and Electronics in Agriculture, 2003, 38(1), 33-44.

Lamb D.W., Hall A., Louis J., Airborne remote sensing of vines for canopy variability and productivity. Australian Grapegrower \& Winemaker, 2001, 449a, 89-92.

Mazzetto F., La centralità dei sistemi informativi aziendali tra management informatizzato e agricoltura di precisione (The centrality of farminformation systems and computerized management in precision agriculture). Proceedings of CITIMAP Workshop, 2006, Piacenza, Italy, 20 April.

Mazzetto F., Calcante A., Mena A., Comparing commercial optical sensors for crop monitoring tasks in precision viticulture. Journal of Agriculture Engineering, 2009, 1, 11-18.

Milics G., Burai P., Lénárt C., Tamás J., Papp Z., Deákvári J., Kovács L., Fenyvesi L., Neményi M., Comparison of multispectral and hyperspectral vegetation indices for prediction of yield and grain quality of spring barley in Hungary. Proceedings of Ageng2008: International conference on agricultural engineering and industry exhibition, agricultural and biosystems engineering for a sustainable world. 2008, Hersonissos, Crete. 23-25 June.

Moshou D., Bravo C., Wahlen S., West J., McCartney A., De Baerdemaeker J., Ramon H., Simultaneous identification of plant stresses and diseases in arable crops using proximal optical sensing and self-organising maps. Precision Agric. (2006), 7: 149-164.

Oberti R., Calcante A., Mazzetto F., Brancadoro L., Tractorbased ultrasonic and optical sensing of grapevine canopy. CD Poster Paper proceedings of 6th European Conference on Precision Agriculture 2007, June $3^{\text {th }}-6^{\text {th }}$, Skiathos, Greece.

Rho G., Zerbetti F., Sancassani G.P., Toffolati S., Vercesi A., Verifica di diversi metodi di rilevamento di infezioni causate da Plasmopara viticola e Uncinala necator su vite (Testing different methods of detection of infections caused by Plasmopara viticola and Uncinala necator on vines). Atti Giornate Fitopatologiche, 2004, 2, 205-212.

Schumann A.W., Zaman Q.U., Software development for real-time ultrasonic mapping of tree canopy size. Computers and Electronics in Agriculture, 2005, 47, 25-40.

Scotford I.M., Miller P.C.H., Combination of spectral reflectance and ultrasonic sensing to monitor the growth of winter wheat. Biosystems Engineering, 2004, 87(1), 27-38.

Stamatiadis S., Taskos D., Tsadilas C., Christofides C., Tsadila E., Schepers J.S., Relation of ground-sensor canopy reflectance to biomass production and grape color in two Merlot vineyards. American Journal of Enology and viticulture, 2006, 57(4), 415-422.

Townsend G.R., Heuberger I.W., Methods for estimating losses caused by disease in fungicide experiments. Plant Disease Reporter, 1943, 27(17), 340-343.

Vieri M., Spezia G., Pagni P.P., Ingegneria delle produzioni viticole: stato dell'arte e prospettive future (Vine production engineering: state of the art and future prospects), Italus Hortus, 2010, 17(1), 33-57.

Zaman Q.U., Schumann, A.W., Hostler, H.K., Estimation of citrus fruit yield used ultrasonically-sensed tree size. Applied Engineering in Agriculture, 2006, 22(1), 39-44. 


\section{SUMMARY}

This paper considers the possibility to use ground sensing technologies that can be employed directly in vineyards. The aim of this work is to evaluate contemporarely the canopy health and vigour status of vines through the use of a mobile monitoring system; this, in order to investigate the possibility to realize a pathological diagnosis in vineyards. To achieve this objective optical and analogue devices were tested: a) GreenSeeker RT100, a commercial optical device calculating NDVI in real time; b) ultrasonic sensors for canopy thickness estimation. A DGPS receiver was employed for geo-reference data collected while travelling in the vineyards.

Tests were conducted in a commercial vineyard which included rows treated and non-treated with agrochemicals. Data coming from the automatic mon- itoring were compared to manual morphological and physiological observations carried out to characterize the phytosanitary status of the canopy.

Optical data were processed in order to obtain NDVI maps. They clearly showed differences in canopy vigour evolution in the two examined groups, and low vegetative vigour in areas infected by Plasmopara viticola (as confirmed by manual assessment). Maps of percentage infection index $(\mathrm{I} \% \mathrm{I})$ were produced according to pathological manual survey results. The comparison between I\%I and NDVI maps confirmed, at a qualitative level, the real vine phytosanitary status.

The integration of UCT and NDVI values allows the identification of diseased vineyard areas among zones presenting critical vegetation conditions.

Keywords: ground sensing, NDVI, canopy thickness, vegetative vigour. 
